Background: Glucocorticosteroids (GCS) are widely used in the treatment of rheumatoid arthritis (RA) as bridge-therapy. Though, according to last recommendations for the treatment of RA GCS should be considered in short-term and different dose regimens and routes of administration and should be tapered as rapidly as clinically feasible. But in some cases, patients received GCS for a long period in low doses $(<7.5 \mathrm{mg} /$ day prednisone equivalent). It is well known, that long-term GCS use is associated with osteoporosis and increased risk of fracture, even at low daily doses. On the other hand, RA itself leads to the changes in the biomechanical properties of bones through the increased production of pro-inflammatory cytokines. Furthermore, immobilization due to pain from inflamed joints and impairment of physical activity are in response for osteoporosis formation. In addition, patients with RA are often co-prescribed a proton pump inhibitor, which have a reported effect on occurrence of osteoporosis. Taking into consideration all mentioned above patients with RA, receiving GCS therapy reveal high risk for osteoporosis and fracture formation and require corresponding treatment.

Objectives: The aim of this study is to evaluate the effect of 12 months treatment with denosumab (bone-modifying agent) in patients with RA, continuing to receive GCS.

Methods: 50 female patients with RA (mean age $54 \pm 6.3$ years) were enrolled in this study. Duration of RA was $10.5 \pm 3.2$ years. All patients received prednisone $15,3 \pm 10,25 \mathrm{mg} /$ day with gradually escalation of dose for $\geq 12$ months. As DMARD therapy patients received methotrexate dose in average 15-20mg/week $(75 \%)$, leflunomide $20 \mathrm{mg} /$ day $(25 \%)$. Bone mineral density (BMD) is measured in all patients by Dual-energy X-ray absorptiometry (DEXA) at baseline and 12 months after treatment with denosumab. All patients received denosumab $60 \mathrm{mg}$ subcutaneously once every 6 months.

Results: The measurement of BMD at baseline revealed the following results: T-score in lumbar spine was $-1,95 \pm 1,36$ and in total hip $-1,64 \pm 0,94$ with high major osteoporotic fracture risk. All patients completed the study. The BMD after 12 months significantly increased both in lumbar spine $+4,2 \%(p<0,001)$ and in total hip $+2,1 \%(p<0,001)$.

Conclusion: Denosumab should be considered as a drug of choice in RA patients, continuing to receive GCS. Further large investigations are needed to assess the BMD after discontinuation of denosumab and evaluate fracture risk in this population of patient.

References:

[1] J.Compston. Glucocorticoid-induced osteoporosis: an update. Endocrine. 2018; 61(1): 7-16. doi: 10.1007/s12020-018-1588-2

[2] A.Giovanni, S.Kenneth. Glucocorticoid-induced osteoporosis update. Current Opinion in Rheumatology: 2019;31(4): 388-393. doi: 10.1097/ BOR.0000000000000608

Disclosure of Interests: None declared

DOI: 10.1136/annrheumdis-2020-eular.2793

\section{AB0910 $\quad$ SARCOPENIA AND BONE MINERAL DENSITY IN MEN WITH CORONARY HEART DISEASE}

T. Raskina ${ }^{1}$, I. Grigoreva ${ }^{1}$, J. Averkieva ${ }^{1}$, A. Kokov ${ }^{2}$, V. Masenko ${ }^{2} .{ }^{1}$ Federal State Educational Institution of Higher Education "Kemerovo State Medical University," Kemerovo, Russian Federation; ${ }^{2}$ Research Institute for Complex Problems of Cardiovascular Diseases, Siberian Branch, Russian Academy of Medical Sciences, Kemerovo, Russian Federation

Objectives: To examine bone mineral density (BMD) in men with coronary heart disease (CHD), depending on the state of the muscle mass, strength and function.

Methods: 79 men aged over 50 years with verified $\mathrm{CHD}$ were examined (mean age $63(57 ; 66)$ years)

The BMD and T-criterion (standart deviation, SD) of the femoral neck and lumbar spine (L1-L4) were evaluated using dual-energy $x$-ray absorptiometry (DXA) on the Lunar Prodigy Primo bone densitometer (USA). The following reference intervals were used: normal BMD values (T-criterion $\geq-1$ ), osteopenia $(\mathrm{OPe})$ (T-criterion from -1 to -2.5 ), and osteoporosis (OP) (T-criterion <-2.5).

To assess muscle mass, the total area $\left(\mathrm{cm}^{2}\right)$ of the lumbar muscles of the axial section at the level of the 3rd lumbar vertebra (L3) was determined using multispiral computed tomography on a 64-slice computer tomograph "Somatom Sensation 64" (Siemens AG Medical Solution, Germany). The ratio of the obtained index of the area of skeletal muscle to the square of the patient's growth index determined the "skeletalmuscular index L3" (SMI). The media considered the threshold value to be $52.4 \mathrm{~cm}^{2} / \mathrm{m}^{2}$.

Results: The femoral neck BMD in the examined patients was $0.96(0.89 ; 1.03)$ $\mathrm{g} / \mathrm{cm}^{2}$, which corresponds to $-0.50(-1.00 ; 0)$ SD according to the T-criterion, in the lumbar spine $-1.23(1.11 ; 1.32) \mathrm{g} / \mathrm{cm}^{2}$ and $0.4(-0.50 ; 1.20) \mathrm{SD}$ according to the T-criterion.

In accordance with the recommendations of the European working group on sarcopenia in Older people (EWGSOP, 2010, 2018), the patients were divided into 3 groups: 31 patients without sarcopenia (group 1), 21 patients with isolated muscle loss (presarcopenia) (group 2) and 27 patients with sarcopenia (group 3). BMD in the femoral neck in the group of patients without sarcopenia was 0.96 $(0.72 ; 1.26) \mathrm{g} / \mathrm{cm}^{2}$, which corresponds to $-0.50(-0.8 ; 0.2) \mathrm{SD}$ according to the T-criterion, in the lumbar spine $-1.19(1.10 ; 1.275) \mathrm{g} / \mathrm{cm}^{2}$ and $0.1(-0.6 ; 0.8) \mathrm{SD}$ according to the T-criterion. BMD in the femoral neck in the group of patients with presarcopenia (group 2) $-0.995(0.94 ; 1.04) \mathrm{g} / \mathrm{cm}^{2}$ and $-0.3(-0.70 ; 0) \mathrm{SD}$ according to the T-criterion, in the lumbar spine $-1.32(1.24 ; 1.40) \mathrm{g} / \mathrm{cm}^{2}$ and 1.20 $(0.50 ; 1.90) \mathrm{SD}$ according to the T-criterion. In patients with established sarcopenia (group 3), the following indicators of BMD and T-criterion were recorded: 0.95 $(0.845 ; 0.98) \mathrm{g} / \mathrm{cm}^{2}$ and $-0.60(-1.40 ;-0.40) \mathrm{SD}$ and $1.23(0.085 ; 1.31) \mathrm{g} / \mathrm{cm}^{2}$ and $0.4(-0.8 ; 1.1) S D$ in the femoral neck and lumbar spine, respectively.

A comparative analysis of the results of the DXA found that patients with sarcopenia had a significant decrease in the BMD and T-criterion in the femoral neck compared to patients with presarcopenia $(p=0.039$ and $p=0.040$, respectively). There were no differences between the groups of patients without sarcopenia and with sarcopenia and presarcopenia $(p>0.05)$.

It was found that patients with sarcopenia had significantly lower BMD and T-criterion in the lumbar spine compared to patients with presarcopenia $(p=0.017$ and $p=0.0165$, respectively). The values of the BMD and T-criterion in the groups of patients without sarcopenia and with presarcopenia and sarcopenia in the lumbar spine were comparable ( $p>0.05$ ).

Conclusion: The presence of sarcopenia is associated with loss of BMD in the femoral neck and in the lumbar spine. The results obtained confirm the high probability of common pathogenetic links between OP and sarcopenia.

Disclosure of Interests: None declared

DOI: 10.1136/annrheumdis-2020-eular.5401

\section{AB0911 $\quad$ PREVALENCE AND RISK FACTORS OF HIP FRACTURE ASSOCIATED WITH OSTEOPOROSIS IN A GERIATRIC POPULATION FROM COLOMBIAN NORTH EAST.}

M. Romero ${ }^{1}$, M. Cadena ${ }^{1}$, J. Osma ${ }^{1}$, Y. Santamaria ${ }^{1,2}{ }^{1}{ }^{1}$ Universidad Industrial de Santander, Bucaramanga, Colombia; ${ }^{2}$ Universidad de Antioquia, Medellin, Colombia

Background: Hip fracture is a frequent cause of hospital admission in older adults. ${ }^{1}$ The prevalence of hip fracture associated with osteoporosis in the elderly is $18 \%$ in women and $6 \%$ in men. ${ }^{2}$ Likewise, the attention of this event requires an approximate value of 2,943 dollars, which represents an average of $18,95 \%$ of the per capita income of most countries. ${ }^{3}$ It is also established that appropriate and timely treatment of osteoporosis can prevent the appearance of fractures. ${ }^{4}$

Objectives: The aim of this study was to determine the prevalence of hip fracture associated with osteoporosis, as well as the associated factors to its presentation in a geriatric population in Colombia.

Methods: Cross-sectional study that included 130 patients over 65 years old who consulted the University Hospital of Santander with hip fracture. The main variable of exposition was the medical history of osteoporosis. Descriptive analysis was performed with absolute and relative frequency measurements for the qualitative variables and central tendency measures and dispersion according to the distribution of the variables. Subsequently, the bivariate logistic regression analysis was performed to identify the associated risk variables. The analysis was performed with the Stata 12.0 Software.

Results: From the 130 patients included in the study, 33.85\% corresponded to the male gender. The average age was 82.49 years with a DS of 8.35 years. The median length of hospital stay was 17.5 days with an interquartile range of 11 to 26 days. The most common comorbidity was hypertension in $65.38 \%$, followed by diabetes and COPD in $21.54 \%$, heart failure in $19.23 \%$ and chronic kidney disease in $17.69 \%$. The median Charlson score was 5 with an interquartile range between 4 and 6 points. $13.85 \%$ of the patients admitted had concomitant osteoporosis, $77.7 \%$ of them were women and $8,46 \%$ of them had severe osteoporosis, with history of prior fracture, without treatment. In the bivariate analysis an association was found between having COPD (OR: 4.89, 95\% Cl 1.71-13.95, $\mathrm{p}=0.003$ ), dementia (OR: $3.20,95 \% \mathrm{Cl} 1.05-19.56, \mathrm{p}=0.044)$, malnutrition (OR: 3.42, IC95 \% $1.10-10.60, p=0.032$ ), and osteoporosis associated with hip fracture at hospital admission. Likewise, a greater probability was found for the development of in-hospital pneumonia (OR: 2.48, 95\% Cl $1.14-7.98, p=0.04$ ) in patients with osteoporosis compared to those who did not have bone disease. Conclusion: $13.85 \%$ of patients who entered due to hip fracture had osteoporosis as comorbidity, data comparable to that previously reported. Variables associated with the presence of osteoporosis at admission in patients with hip fracture were found like history of COPD, dementia, and malnutrition, which makes it likely that those patients with pathologies that decrease physical activity or food intake can impact in an important way the appear ance of osteoporosis. One of the most important contributions of this study 
is the identification of in-hospital complication (pneumonia), which should be actively monitored in these patients.

References:

[1] Falaschi P (Paolo), Marsh DR. Orthogeriatrics. Springer; 2017.

[2] Cooper C, Campion G, Melton LJ. Hip fractures in the elderly: A world-wide projection. Osteoporos Int. $1992 \mathrm{Nov} ; 2(6): 285-9$.

[3] Mohd-Tahir NA, Li SC. Economic burden of osteoporosis-related hip fracture in Asia: a systematic review. Vol. 28, Osteoporosis International. Springer London; 2017. p. 2035-44.

[4] Solimeo SL, Mccoy K, Reisinger HS, Adler RA, Sarrazin MV. Factors Associated With Osteoporosis Care of Men Hospitalized for Hip Fracture: A Retrospective Cohort Study. 2019;

Disclosure of Interests: None declared

DOI: 10.1136/annrheumdis-2020-eular.5129

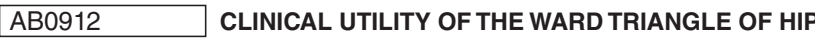 BONE DENSITOMETRY: DATA FROM AN FLS UNIT}

J. Rosas $^{1}$, A. Pons ${ }^{1}$, C. Cano ${ }^{1}$, E. Ivars ${ }^{2}$, M. Lorente Betoret ${ }^{2}$, J. M. Senabre Gallego $^{1}$, G. Santos Soler ${ }^{1}$, J. A. Bernal ${ }^{2}$, J. A. García-Gómez ${ }^{3}$, X. Barber ${ }^{4}$ on behalf of AIRE-MB Group. ${ }^{1}$ Hospital Marina Baixa, Rheumatology, Villajoyosa (Alicante), Spain; ${ }^{1}$ Hospital Marina Baixa, Rheumatology, Villajoyosa (Alicante), Spain; ${ }^{3}$ Hospital General Universitario de Elche, Infectious Disease, Elche, Spain; ${ }^{4}$ Universidad Miguel Hernández de Elche, ClO, Elche (Alicante), Spain

Objectives: To evaluate the clinical utility of Ward's triangle (W) of bone densitometry (BMD) of the hip in a population of postmenopausal women referred to BMD from a FLS Unit coordinated by Rheumatology (FLS-REU).

Methods: Retrospective study, which includes, after informed consent, postmenopausal women referred by any department of specialized medicine or primary care medicine, of the health department, to the FLS-REU Unit of our center, during the period of February 2010 to October 2019.

General patient data were collected (age, gender), and risk factors for OP. BMD of the lumbar spine (CL) and hip (femoral neck, total hip and W) was performed, except if there was lumbar surgery, severe scoliosis, or a bilateral hip prosthesis. The BMD outcome was distributed in normal (T index [Ts] to -1 SD), osteopenia (Ts: -1.1 to $-2.5 \mathrm{SD}$ ) and OP (Ts: <-2.5 SD), separated into two groups: mild OPmoderate (Ts: from <-2.5 DE to $-3 \mathrm{DE})$ or severe OP (Ts: <-3 DE).

Results: 5,740 postmenopausal women referred for BMD are included, with the W result available (Table 1). The result of the mean Ts (SD) was: in CL: -1.49 (1.48) SD, femoral neck: -1.33 (1.11) SD and in W: -2.05 (1.12) SD. In 947 (16\%) women, the $W$ was normal, with a mean Ts: -0.28 (1.12) SD; osteopenia in 2,606 $(45 \%):-1.83(1,12)$ SD and OP in 2,197 (39\%) SD, of which $1,010(61 \%)$ had mild-moderate OP and 967 (49\%), severe OP.

The table shows the BMD results of $\mathrm{W}$ and $\mathrm{CL}$, the correlation coefficient between them being $0.52(0.5-0 . P<0.001)$, although with a Kappa coefficient of $0.26(0.24-0.28 . P=0)$. The probability that a result in $\mathrm{W}$ of normal $\mathrm{BMD}$ is normal also in CL is $73 \%(70 \%-76 \%)$, in osteopenia in both: $47 \%(45 \%-49 \%)$ and OP: $46 \%$ (44 \% -48\%). In the analysis by ROC curve, the cut-off point of Ts in W for osteopenia in CL is -1.85 SD (sensitivity: 0.648, specificity: 0.649, with AUC: 00.702. [0.687-0.716]) and for OP in CL $-2.35 \mathrm{DE}$ (sensitivity: 0.69 , specificity: 0.70 , with AUC: 0.757 [0.744-0.770])

\begin{tabular}{|c|c|c|c|c|c|}
\hline & \multicolumn{5}{|c|}{ LUMBAR SPINE (LS) } \\
\hline & Normal & Osteopenia & $\begin{array}{l}\text { Osteoporosis } \\
\text { (OP) }\end{array}$ & $\begin{array}{c}\text { OP } \\
<-2.5 \text { a }-3 \\
\text { SD }\end{array}$ & $\begin{array}{c}\text { OP } \\
<-3.0 \text { SD }\end{array}$ \\
\hline Ward normal & 681 & 211 & 39 & 26 & 13 \\
\hline N (\%): $947(16)$ & $0.41 \pm 1.78$ & $-1.61 \pm 1.78$ & $-2.95 \pm 1.78$ & $-2.7 \pm 1.78$ & $-3.46 \pm 1.78$ \\
\hline $\begin{array}{l}\text { Tscore: }-0.28 \pm 1.12 \text { SD } \\
\text { Ward osteopenia }\end{array}$ & 899 & 1.192 & 463 & 310 & 153 \\
\hline $\begin{array}{l}\mathrm{N}(\%): 2.606(45) \\
\text { Tscore: }-1.83 \pm 1.12 \mathrm{SD}\end{array}$ & $-0.07 \pm 1.48$ & $-1.73 \pm 1.48$ & $-2.96 \pm 1.48$ & $-2.72 \pm 1.48$ & $-3.43 \pm 1.48$ \\
\hline $\begin{array}{l}\text { Ward Osteoporosis } \\
N(\%): 2.187(39) \\
\text { Tscore: }-3.07 \pm 1.13 \text { SD }\end{array}$ & $\begin{array}{c}346 \\
-0.19 \pm 1.48\end{array}$ & $\begin{array}{c}800 \\
-1.83 \pm 1.48\end{array}$ & $\begin{array}{c}975 \\
-3.23 \pm 1.48\end{array}$ & - & - \\
\hline $\begin{array}{l}\text { Ward Osteoporosis }<-2.5 \\
\text { a-3 SD }\end{array}$ & $\begin{array}{c}188 \\
-0.16 \pm 1.48\end{array}$ & $\begin{array}{c}416 \\
-1.83 \pm 1.48\end{array}$ & - & $\begin{array}{c}173 \\
-2.77 \pm 1.48\end{array}$ & $\begin{array}{c}378 \\
-3.08 \pm 1.48\end{array}$ \\
\hline $\mathrm{N}: 1.010(51)$ & & & & & \\
\hline $\begin{array}{l}\text { Tscore: }-2.78 \pm 1.12 \text { SD } \\
\text { Ward Osteoporosis <-3 SD }\end{array}$ & 114 & 304 & - & 193 & 327 \\
\hline $\begin{array}{l}\mathrm{N}: 967(49) \\
\text { Tscore: }-3.51 \pm 1.13 \mathrm{SD}\end{array}$ & $-0.24 \pm 1.48$ & $-1.84 \pm 1,48$ & & $-2.78 \pm 1.48$ & $-3.73 \pm 1.48$ \\
\hline
\end{tabular}

Conclusion: 1.For clinical practice, the usefulness of the $\mathrm{W}$ result is low, although if the BMD result is normal, there is a $73 \%$ probability that in $C L$ it will also be. 2 . The correlation between the result of $\mathrm{W}$ and $\mathrm{CL}$, although significant, is slight. 3. The cut-off points of Ts, with better sensitivity and specificity, that correlate a W osteopenia or osteoporosis with the result in $\mathrm{CL}$ is -1.85 and -2.35 $\mathrm{SD}$, respectively.

Acknowledgments: The study was supported by a research grant from the Association for Research in Rheumatology of the Marina Baixa (AIRE-MB).

Disclosure of Interests: None declared

DOI: 10.1136/annrheumdis-2020-eular.4765

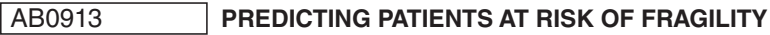 FRACTURE WITH NORMAL BONE MINERAL DENSITY: AN OBSERVATIONAL STUDY}

C. Saleh ${ }^{1}$, M. Bukhari ${ }^{1}$, S. M. Bilgrami ${ }^{1} .{ }^{1}$ Royal Lancaster Infirmary, Rheumatology, Lancaster, United Kingdom

Background: There is an increased risk of low-trauma fracture as bone mineral density (BMD) decreases, however a large proportion of these fragility fractures occur in those without osteoporosis or osteopenia. The widely used FRAX tool uses femoral neck (FN) BMD, amongst other parameters, to predict fracture risk. In those with nor mal BMD, data is lacking on the weight these other parameters hold in predicting future risk. Indeed, FN BMD can be facultative in the estimation of risk when using FRAX. Objectives: To establish predictors of fragility fracture in a patient cohort referred for BMD estimation, subsequently found to have bilateral FN BMD of greater than 1.

Methods: A cohort of patients in the North West of England referred between 2004 and 2014 for BMD estimation, with both left and right FN BMD of greater than 1 were identified. Patient parameters identified and analysed included age at scan, gender BMD at left hip, body mass index (BMI), fat mass, family history of fracture, alcohol history of 3 or more units per day, smoking status, rheumatoid arthritis (RA), and steroid exposure. Patients with fragility fracture were compared with those without fracture. Chi-square test and T-test were applied to categorical and continuous data respectively. Further univariate and multivariate logistic regression models were fitted to determine parameters associated with future fracture risk.

Results: 619 patients with bilateral FN BMD of greater than 1 were identified and included in analysis. Mean age at scan was 54 years (SD 11.82) and 542 $(87.56 \%)$ were female. $92(14.86 \%)$ patients had a fragility fracture. Mean left FN BMD was 1.91 (SD 0.71), and mean right FN BMD was 1.92 (SD 0.68). Results of the univariate analysis are described in Table 1 below.

Table 1. Logistic regression analysis of patient parameters with unadjusted and adjusted odds ratios for fragility fracture

\begin{tabular}{lccc}
\hline Predictor & $\begin{array}{c}\text { Unadjusted odds ratio Odds ratio adjusted for } \\
\text { age }(95 \% \mathrm{Cl})\end{array}$ & $\begin{array}{c}\text { Odds ratio adjusted } \\
\text { for age and gender } \\
(95 \% \mathrm{Cl})\end{array}$ \\
\hline Age at scan (years) & $0.99(0.98-1.01)$ & - & - \\
Gender & $1.37(0.66,2.84)$ & $1.34(0.64,2.80)$ & - \\
BMD at left hip & $0.34(0.03,4.05)$ & $0.37(0.03,4.37)$ & $0.50(0.03,7.67)$ \\
BMI & $1.07(1.03,1.10)$ & $1.07(1.03,1.10)$ & $1.07(1.03,1.10)$ \\
Fat mass & $1.00(1.00,1.00)$ & $1.00(1.00,1.01)$ & $1.00(1.00,1.01)$ \\
Parent fractured hip & $0.99(0.57,1.70)$ & $0.97(0.56,1.68)$ & $0.94(0.54,1.64)$ \\
Alcohol (3 or more & $1.16(0.47,2.86)$ & $1.16(0.47,2.87)$ & $1.16(0.47,2.89)$ \\
$\quad$ units/day) & $1.40(0.89,2.21)$ & $1.40(0.89,2.21)$ & $1.42(0.90,2.23)$ \\
Current smoker & $0.83(0.32,2.19)$ & $0.85(0.32,2.24)$ & $0.86(0.34,2.27)$ \\
Rheumatoid arthritis & $0.53(0.30,0.96)$ & $0.53(0.30,0.96)$ & $0.54(0.30,0.98)$ \\
Steroid exposure & & &
\end{tabular}

Conclusion: Steroid exposure and body composition parameters influence fracture risk in this group pf patients with normal BMD, further work will be done looking at the types of fractures and other parameters in this group of patients. Disclosure of Interests: Christopher Saleh: None declared, Marwan Bukhari Speakers bureau: Bristol-Myers Squib, UCB celltech, Roche/Chugai, Pfizer, Abbvie, Merck, Mennarini, Sanofi-aventis, Eli-Lilly, Janssen, Amgen and Novartis. Syed Mujtaba Bilgrami Speakers bureau: Pfizer DOI: 10.1136/annrheumdis-2020-eular.4544

\section{$\mathrm{AB} 0914$}

\section{BONE LOSS AND NEW FRACTURES WITH} DENOSUMAB TREATMENT

C. Sanguesa ${ }^{1}$, I. Casafont-Solé ${ }^{1}$, A. Nack ${ }^{1}$, S. Holgado Pérez ${ }^{1}$, M. MartínezMorillo $^{1}$, M. Aparicio Rovira ${ }^{1}$, Á. Prior-Español ${ }^{1}$, M. Aparicio Espinar ${ }^{1}$, A. Riveros ${ }^{1}$, L. Mateo ${ }^{1}$, A. Olive ${ }^{1}$, L. Gifre ${ }^{1} .{ }^{1}$ Germans Trias i Pujol University Hospital, Rheumatology, Badalona, Spain 